\title{
Approaches to energy-efficient activities of business entities in industrial sectors of the economy in Russia and European countries
}

\author{
Tatiana Meshcheryakova ${ }^{1, *}$ \\ ${ }^{1}$ Department of Management and Innovation, National Research University "Moscow State University of Civil Engineering”, NRU \\ MGSU, Moscow, Russia
}

\begin{abstract}
The article contains an analysis of the statistical data of the bodies of Russian and European statistics on end-users of energy resources. The study focuses on industrial activities, which means that the work identifies the place where the most energy-intensive activities are highlighted and the problems of reducing energy costs are considered. The practice of using the energy service contract mechanism in the Russian Federation and the EU is analyzed, and the prospects for its distribution in industrial activities are assessed. The resulting issue is the development of recommendations for improving the energy efficiency of industrial enterprises, taking into account the accumulated international experience and current trends in the sustainable development of the economies of the EU and the Russian Federation.
\end{abstract}

\section{Introduction}

The aim of the study is to create uniform methodological approaches to the energy-efficient activities of business entities in the industrial sectors of the economy in the Russian Federation and the EU.

The object of the research is energy-intensive industrial activities in the Russian Federation and the EU.

The subject of research is defined as a process in which there is a problem area - improving the energy efficiency of economic entities in the industrial sectors of the economy of the Russian Federation and the EU.

To achieve this goal, the following tasks were set and solved:

- a graphical analysis of statistical data on end-users of energy resources in the Russian Federation and EU countries;

- The most energy-intensive EU countries were identified, as well as the types of industrial activity that are the most significant energy consumers;

- analysis of policy measures for energy saving and energy efficiency improvement of the Russian and European economies, including road maps for the development of industrial economic activities;

- presented recommendations for improving the energy efficiency of industrial enterprises, taking into account accumulated international experience and current trends in the sustainable development of the economies of the EU and the Russian Federation.

\section{Materials and Methods}

The study is desk-based, as it was conducted on the basis of open information sources of statistical bodies, as well as using reference legal systems containing official legal documents. The base year of the study is 2007. During this period, a new approach to resource conservation begins to take shape in the Russian economy, and on the basis of the Presidential Decree, the key law on Energy Saving and Energy Efficiency \# 261 is created, the first program documents on energy saving at the national level are developed. For a comparative retrospective analysis of European data, a sample has also been taken from 2007 to the latest official data for 2017 .

The methods used in the analysis of Rosstat and Eurostat data on end-users of energy resources and energy balances are the compilation and grouping of materials for statistical monitoring of statistical bodies, the use of graphical methods for presenting statistical information.

For the predictive assessment of the issues of development of energy-efficient activities of economic entities in the industrial sectors of the Russian economy and in the EU countries, the analogy method was used, based on the experience of developing similar phenomena and processes.

To assess the forecast in the existing problem areas using the energy service contract (ESC) mechanism in the Russian Federation, reference situations in industrialized EU countries are used, based on such main features that give reason to talk about the coincidence of the direction of events.

\footnotetext{
* Corresponding author: t.meshcheryakova@mail.ru
} 


\section{Results}

Let us present the results of the analysis of data on the final energy consumption in the EU countries.

Eurostat data reveals a trend in energy consumption (Fig. 1) [1].

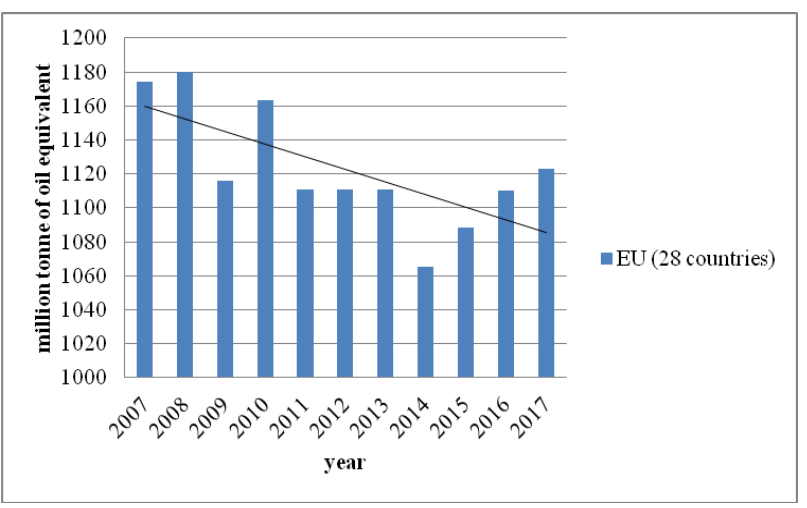

Fig. 1. Dynamics of total final energy consumption by EU countries.

Over the past four years there has been an increase in energy demand. To identify the causes of such dynamics, we will present Eurostat data for countries that are major energy consumers. (Fig. 2) [1].

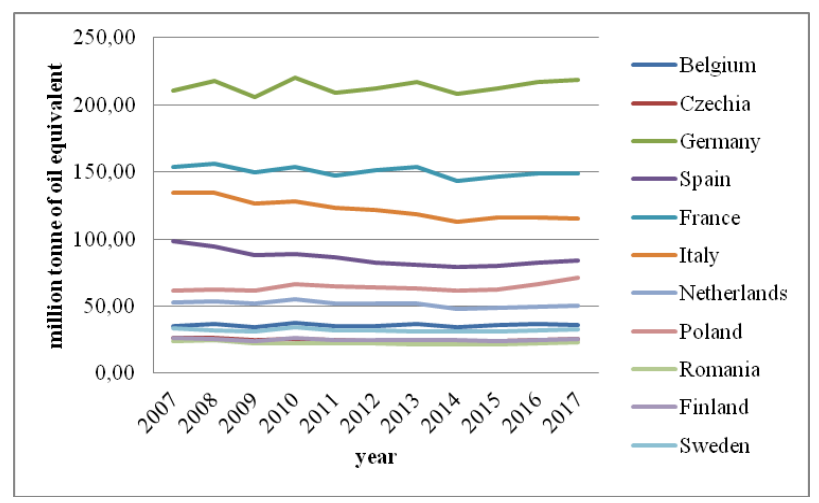

Fig. 2. Dynamics of final consumption of energy resources of EU countries.

The graph shows the EU countries, conditionally defined, as the largest consumers of energy resources. The sample is presented in conditional boundaries determined by the annual need for more than 20 Mtoe. Comparison of countries in terms of the baseline level of growth and absolute growth indicator shows that Poland is the least efficient of the EU countries to implement energy saving measures (Fig. 3) [1].

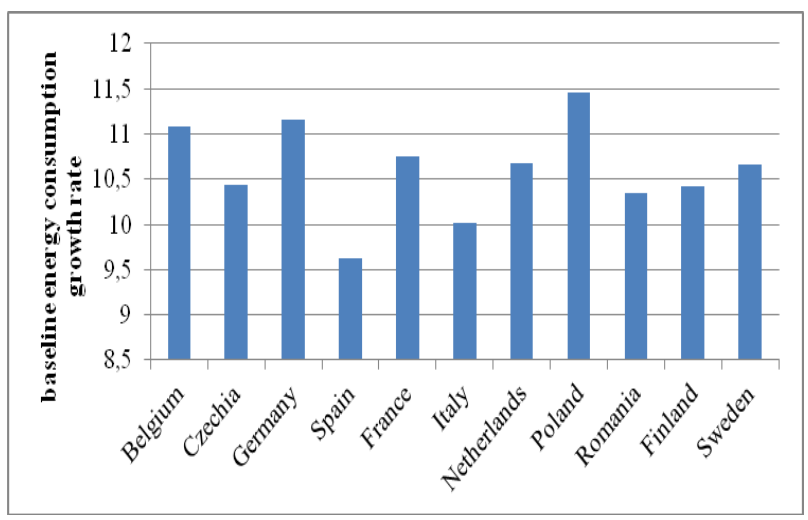

Fig. 3. The growth rate of energy consumption over 7 years by EU countries.

However, for an objective comparison of the data, we provide information on the share of energy consumption in GDP by the largest energy consumers in the EU (Fig. 4) [1].

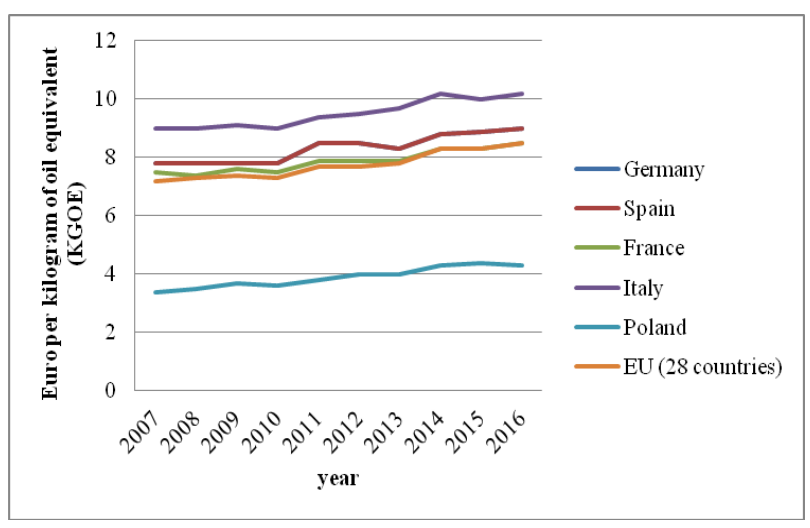

Fig. 4. The dynamics of the energy intensity of most EU countries.

The energy intensity of the EU countries is growing every year, and there are some contradictions. The most energy-intensive of these countries is Italy, and the most energy-intensive economies in the EU are Ireland and Denmark (they are not shown in the graph), but they do not have significant industrial potential, although they are part of the Organization for Economic Cooperation and Development (OECD). Producing countries or industrialized ones is a category that is not strictly defined by scientists, but it is customary in the world economy to consider OECD countries.

Consider the key groups of end-users of energy in the EU by type of economic activity (Fig. 5). 


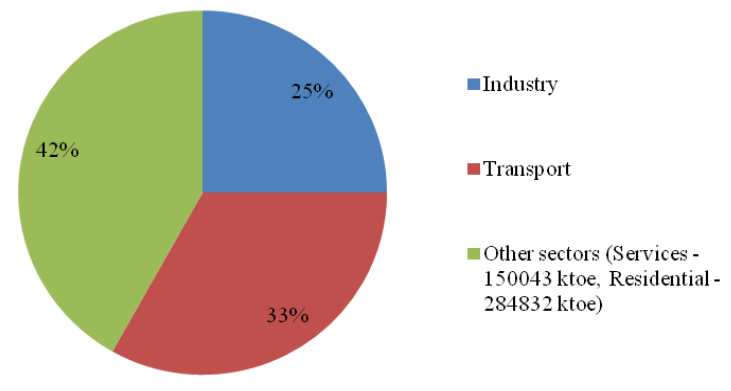

Fig. 5. End-users of energy resources by type of activity in the EU.

Energy costs in industrial activities reflect the company's performance indicators and affect the energy intensity of the economies of industrialized countries. In this case, special attention should be paid to such energyintensive industries as: Chemical and Petrochemical (51356 ktoe), Iron and Steel (48954 ktoe), Non-metallic minerals (33851 ktoe), Paper, Pulp and Printing (33848 ktoe) (Fig. 6) [1].

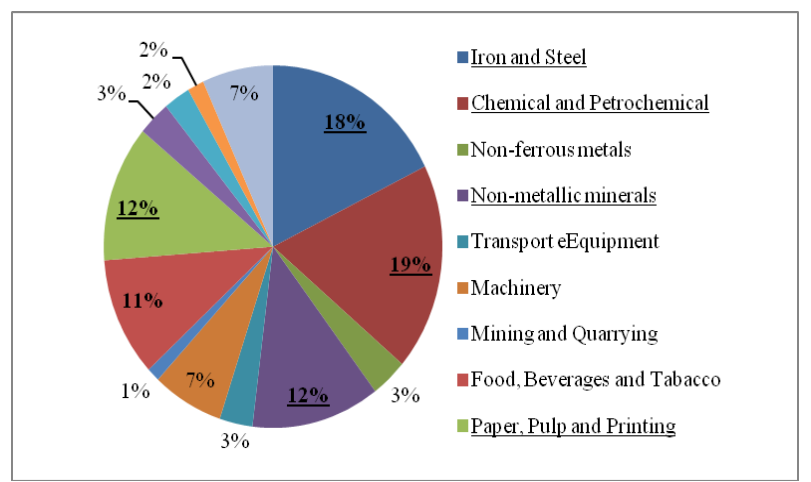

Fig. 6. Final industrial energy resources by type of industrial activity in the EU.

Unlike the EU countries in Russia, industry is the largest end-user of energy resources. For comparison, we give the energy balance data on the most energyintensive types of manufacturing industry. (Fig. 7).

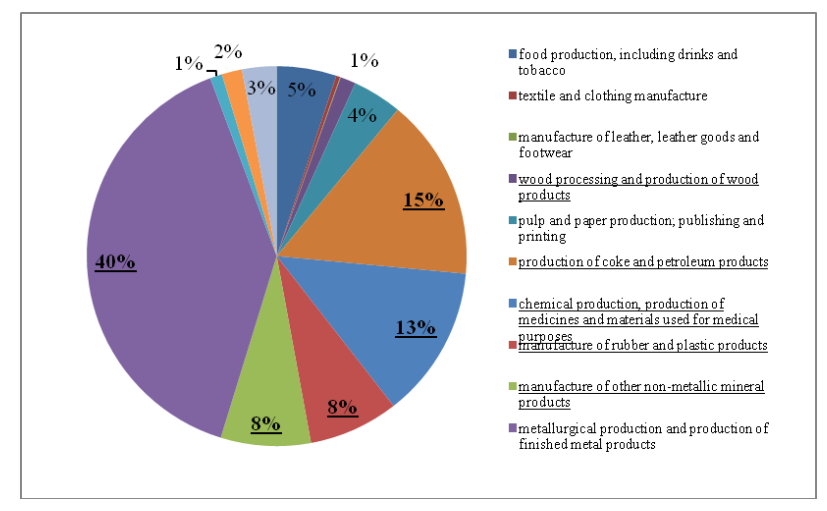

Fig. 7. End users of energy resources by type of industrial activity in the Russian Federation.

\section{Discussion}

In Russia, the activation of energy-efficient state policy has been observed since 2008. The issues of energy saving and energy efficiency improvement of the economy received special development in 2009 after the introduction of the Federal Law \# 261 "On energy saving and energy efficiency improvement and on amendments to certain legislative acts of the Russian Federation". However, for a long time there was no purposeful system of energy-efficient development of industrial enterprises. In 2018, the Order of the Government of the Russian Federation \# 703 approved a comprehensive plan of measures to increase the energy efficiency of the economy of the Russian Federation, which provides for the implementation of measures to increase the energy efficiency of the Russian economy, including in relation to industrial enterprises. The plan is aimed at ensuring the modernization of fixed assets, increasing the contribution of the technological factor to reducing the energy intensity of gross domestic product to at least 1.5 percent per year, as well as ensuring the reduction of the technological gap between the Russian Federation and the leading countries. Among other things, the plan provides for the creation of a rating system for industrial enterprises in Russia that take measures in the field of energy saving and energy efficiency and introduce a mechanism to stimulate industrial enterprises in order to implement energy saving and energy efficiency measures [2-5].

At the moment, the implementation of a plan for the energy-efficient development of the Russian economy requires the development of methodological foundations that allow one to assess the level of energy efficiency of an industrial facility, complex and / or enterprise. For these purposes, it is necessary to create a methodology for the classification of industrial facilities by level of energy efficiency [6-8]. However, the solution of this task will require the formation of standards for the specific values of energy consumption with reference to activities. In an integrated form, the implementation of such a methodical development will be limited to the creation of registers of energy-intensive industrial enterprises classified according to All-Russian Classification of Economic Activities (OKVED).

The practice of implementing energy-efficient measures should be based on the use of ESCs, which has established itself in EU countries, but has not yet received the necessary scale to use for industrial enterprises. The advantages of this mechanism are obvious. The most significant arguments for the benefit of ESCs are low customer risks and the lack of initial investment costs [9-11]. The problem of the proliferation of an ESC mechanism for industry can be solved if the following recommendations are implemented:

-it is required to renew the mandatory energy inspections in terms of energy-intensive industrial enterprises and to form an algorithm for its conduct with the restoration of the corresponding position in the Federal Law; -according to the results of energy audits, it is necessary to oblige the managers of industrial enterprises to 
implement energy-saving measures included in the energy passport application;

-the ESC mechanism should be recommended for the implementation of energy saving measures for selected types of economic activity;

-it is necessary to continue work on exploring opportunities and forming an ESC insurance fund.

\section{Conclusion}

The first priority issue in energy saving and increasing the energy efficiency of industrial enterprises should be the creation of a regulatory framework that allows them to classify industrial facilities according to energy efficiency classes. Industrial facilities are distinguished by their uniqueness and will require time-consuming research from external expert auditors [12-15].

The dynamics of energy consumption indicates that the measures taken to reduce the energy intensity of the leading industrialized economies have not yet brought significant results, despite the fact that the corresponding goals and new benchmarks were set at the level of many governments more than 10 years ago. Sustainable development of economies requires a detailed analysis of existing problems and the development of methodological provisions that can ensure the synergy of all processes that have been functioning for a long time in the field of ecology, environmental protection, economics of industries and energy saving. Insufficient attention is paid to special road maps of the energy efficient policies of industrial enterprises. There is no motivation system capable of attracting the attention of managers of industrial energy-intensive enterprises to the issues of energy saving and energy efficiency of technological processes. The issue of the development of ESCs for industrial enterprises, which can change the approach to the technical re-equipment of industrial enterprises and reduce the costs of budgets of various levels for the implementation of energy-saving measures, has not yet been resolved. The problems of activating the ESC mechanism for industry are relevant not only for the Russian Federation, but also for most EU countries, where such a mechanism is most prevalent in the residential and social sectors.

\section{References}

[1] European Union 2016, Energy balance sheets, Luxembourg: Publications Office of the European Union (2018). DOI: 10.2785/02631.

[2] L. Georgeson, M. Maslin, M. Poessinouw, Geo: Geography and Environment, 4, 1, e00036 (2017). DOI: $10.1002 /$ geo 2.36 .

[3] E. Ganebnykh, A. Mottaeva, T. Larinina, E. Petrova, MATEC Web of Conferences, 170, 01044 (2018). DOI: 10.1051/matecconf/201817001044.

[4] K. Locmelis, D. Blumberga, U. Bariss, Energy Procedia, 147, 202-206 (2018). DOI: 10.1016/j.buildenv.2018.02.012.

[5] P. Bertoldi, F. Diluiso, L. Castellazzi, N. Labanca, T. Serrenho, Energy Consumption and Energy
Efficiency, Publications Office of the European Union, Italy (2018). DOI: 10.2760/6684.

[6] I. Potekhin, V. Mischenko, A. Mottaeva, A. Zheltenkov, E3S Web of Conferences, 33, 03020 (2018). DOI: 10.1051/e3sconf/20183303020.

[7] EEA, Trends and drivers in greenhouse gas emissions in the EU in 2016, European Environment Agency, Copenhagen (2018). DOI: 10.2800/691394.

[8] D. Zhikun, F. Ze, V.W.Y. Tam, B. Yu, L. Shenghan, I.M. Chethana, S. Illankoon, M. Sungkonb, Building and Environment, 133, 32-40 (2018). DOI: 10.1016/j.buildenv.2018.02.012.

[9] A. Bowen, K. Kuralbayeva, E.L. Tipoec, Energy Economics, 72, 263-275 (2018). DOI: 10.1016/j.eneco.2018.03.015.

[10] W.A. Pelser, J.C. Vosloo, M.J. Mathews, Journal of Cleaner Production, 198, 642-653 (2018). DOI: 10.1016/j.jclepro.2018.07.071.

[11] G. Ridauraa, S. Llorens-Cerveraa, C. Carrilloc, I. Buj-Corral, C. Riba-Romevaa, Resources, Conservation and Recycling, 131, 75-85 (2018). DOI: 10.1016/j.resconrec.2017.10.030.

[12] M. Dieterle, Ph. Schäfer, T. Viere, Procedia CIRP, 69, 764-768 (2018). DOI: 10.1016/j.procir.2017.11.058.

[13] T. Meshcheryakova, MATEC Web of Conferences, 106, $06021 \quad$ (2017). $10.1051 /$ matecconf/201710606021.

[14] T. Meshcheryakova, E. Tkacheva, D. Kabanova, MATEC Web of Conferences, 193, 03004 (2018). DOI: $10.1051 /$ matecconf/201819303004.

[15] T. Meshcheryakova, MATEC Web of Conferences, 193, 05005 (2018). DOI: 10.1051/matecconf/201819303004. 